
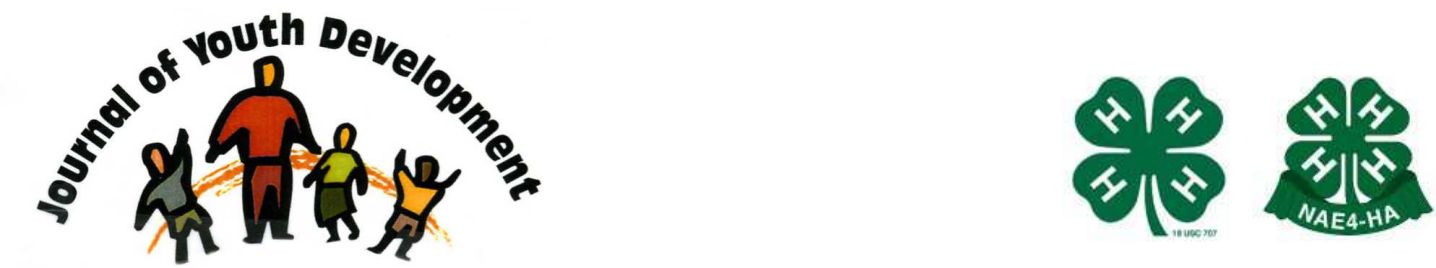

Bridging Research \& Practice

\title{
Attrition in Adolescent After-School Programs: Addressing the Concern via Interviews with Program Dropouts
}

\author{
Lynda Okeke \\ University of Maryland \\ College Park, MD \\ lokeke@cesar.umd.edu
}




\title{
JOURNAL OF YOUTH DEVELOPMENT \\ bridging research and practice

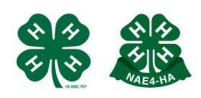

Volume 3, Number 3, Winter 2008

Article 080303FA009

\section{Attrition in Adolescent After-School Programs: Addressing the Concern via Interviews with Program Dropouts}

\author{
Lynda Okeke \\ University of Maryland
}

\begin{abstract}
The purpose of this paper is to address the challenges of attrition in adolescent, voluntary after-school programs (ASPs). Studies show that the after-school hours are a time of elevated juvenile delinquency. Since 1998 there has been a surge in the number of ASPs throughout the United States. Despite this surge, attrition is a major concern and threat to ASPs. Moreover, youth who drop out are rarely asked about their reasons for not attending. Seventy middle schoolaged individuals who were selected to participate in the Baltimore County Middle School After-School Collaboration Project (BCAP) but eventually dropped out are interviewed for this study. Six primary reasons for non-attendance including: a lack of program fidelity, participation in non-family-related after-school activities, participation in family-related after-school activities, program length, boredom, and a lack of quality academic help are identified. The findings indicate a need for programming that is faithful, flexible, and narrow in terms of activities offered.
\end{abstract}

\section{Introduction}

In fiscal year 1998, the federal government provided 40 million dollars to schools across the nation to create and run 21st Century Community Learning Centers (CCLC), which are schoolbased after-school programs. By fiscal year 2001, the funding for CCLCs had increased to \$850 million (Hollister, 2003). State and local agencies followed suit. New York increased funding for its after-school programs from 500,000 to 10 million dollars; Kentucky spent $\$ 37$ million on extended school services, and in 2003 Pennsylvania was considering a bill to spend $\$ 15$ million on their after-school programming (Hollister, 2003). 
The growth in ASPs stems from several important issues. In the 1980s, youth activists began to focus on programming that would target risky behavior of youth including increased sexual activity, drug and alcohol abuse, school dropout, and weak educational performance. The results of such behaviors were perceived to be: growth in teen pregnancy and single parent families, deeper involvement in drug use and sale, growth in gang-related activity and crime, and a lack of basic skills such as literacy and numeracy (Hollister, 2003).

Pursuant to these concerns was the increasing concern over the timing of delinquent behavior. A Carnegie Foundation report (1992) found that a higher proportion of crimes committed by youth were committed between 3 p.m. and 6 p.m. in the afternoon. Furthermore, Snyder, Sickmund, and Poe (1996) found that $22 \%$ of the violent crimes that occurred in South Carolina from 1991 to 1992 occurred between 2 p.m. and 6 p.m. on weekdays. Additionally, Sickmund, Snyder, and Poe, (1997) analyzed data from the National Incident-Based Reporting System from eight states between 1991 and 1993 and found that one in five violent crimes committed by juveniles occurred between the hours of 2 p.m. and 6 p.m. Finally, Gottfredson, Gottfredson, and Weisman (2001) found that the after-school hours were a time of elevated delinquency and that youth who were unsupervised after school were significantly more delinquent at all times than those who attended ASPs.

Indeed, pre-1960s, youth serving organizations such as the Young Men's Christian Association (YMCA), the Boys and Girls Club of America, and the Boy and Girl Scouts were not originally focused on preventing risky behavior, youth crime, and/or teen pregnancy. However, during the $1960 \mathrm{~s}$ and $70 \mathrm{~s}$, the increasing rate of poverty, especially in the inner city, heightened the awareness and concern about juvenile delinquency and risky youth behavior (Hollister, 2003). Towards the late 1980s and early 1990s, greater emphasis was placed on two areas:

1. Curtailing risky behavior and youth crime and

2. Achieving positive outcomes for youth through programming that would build upon the positive assets that youth already possessed (Hollister, 2003).

Towards the latter half of the $90 \mathrm{~s}$, positive youth development became the major focus of afterschool programming (Hollister, 2003).

\section{Literature Review}

The literature on ASPs is varied and extensive. To date, the literature suggests that high quality ASPs provide a plethora of benefits to their participants including: (1) personal attention from caring adults, (2) academic support, (3) development of new friendships, (4) exploration of new interests, (5) a sense of belonging to a group, and (6) the ability to build a sense of selfesteem independent of academic talent (Harvard Family Research Project (HFRP), 2004). These benefits manifest themselves in several protective factors against delinquency and other risky youth behavior including:

1. Increased academic achievement (i.e. higher grades and grade point averages), including recovery from poor academic performance/standing and an interest in furthering one's education,

2. A stronger self-image,

3. Positive social development, 
4. Reductions in risk-taking behavior,

5. Better school behavior, and

6. Fewer absences (HFRP, 2004).

However, the literature is mixed in regards to the definition of high quality programming. The Harvard Family Research Project (2003) provided an overview of 27 evaluations of after-school programs that used experimental and quasi-experimental research designs to make statements about program outcomes. Results from this study suggest that after-school program components and factors that yield greater benefits for youth are programs that match program content and scheduling to participant's needs (i.e. the need to make money or flexible scheduling), programs that keep teens involved with opportunities for leadership, and community service programs.

Lauver and Little (2005) report that paid employment yields greater benefits for teens, especially those in low-income communities, while Rhodes (2004) stresses that caring youthstaff relationships are extremely important. In terms of recruitment and retention strategies, Lauver and Little (2005) state that there are three critical elements to quality after-school programming. These include: "1) a sense of safety and community that is both physical and psychological, 2) committed program staff who develop supportive relationships with youth, and 3) challenging, age-appropriate, and fun program activities" (pg. 72).

Despite the potential benefits of ASPs, attrition is a major concern and threat to their prosperity. In a national evaluation of the 21st Century Community Learning Center program, $25 \%$ of the participants withdrew in the first two months of their ASP (HFRP, 2004). Additionally, in Weisman and Gottfredson's (2001) evaluation of eight different ASPs involved in the Maryland After-School Community Grant Program, "withdrawal interviews" showed that $33 \%$ of the students found the program boring, $19 \%$ of the students had relocated to a different area and could not attend the after-school program and $14 \%$ of the students had transportation problems that caused them to drop out of the program. Indeed, the literature commonly finds that it is difficult to retain teen participants because of a lack of interesting activities.

In a study of three Boys and Girls Clubs of America in New York and five in Boston, about 44\% of the teens in the Boston clubs and 54\% of the teens from the New York clubs cited uninteresting activities as the main barrier to participation (Herrera, \& Arbreton, 2003). Finally, the Harvard Family Research Project (2004) states that most ASPs experience attrition rates of $20-40 \%$ and most commonly lose participants early in the program year due to boredom and/or a lack of interesting program activities.

High attrition rates can be particularly problematic if there are systematic differences between the youth who drop out of ASPs and those who remain in ASPs. For example, youth who drop out of ASPs may come from low-income homes or single parent households. They may have learning disabilities that may negatively impact their ability to perform in an after-school program setting. These youth may be less likely to remain in ASPs than youth without these problems and may be in need of more individualized after-school care. These differences are especially salient for program implementers seeking to positively impact at-risk populations of youth. If more at-risk youth are dropping out of ASPs then the chances of reducing delinquent behavior is diminished. Indeed, the literature on the effects of selection bias tell us that those 
who remain in after-school programs are more likely to perform well in other areas of life regardless of participation in the ASP (HFRP, 2004). In other words, those who choose to participate in ASPs are not necessarily at-risk and are systematically different from those who choose not to participate in ASPs. Similarly, Weisman and Gottfredson's (2001) study shows that students who choose not to participate in ASPs are exactly the type of at-risk students that some ASPs are targeting.

Some interesting qualitative studies have emerged from the New Directions for Youth Development series. In a study conducted by Borden, Perkins, Villarruel, and Stone (2005), the researchers examine the possible correlation between ethnicity and choosing to participate in ASPs. Borden and her colleagues (2005) conducted a qualitative study in which they asked a group of 77 urban youth who reported active participation in a structured program for youth and who identified themselves as Black/African American, Latino, Arab American, or Chaldean about why they chose to participate or not to participate in voluntary ASPs. The youth were also asked to speculate about the reasons for participation and non-participation of other youth in their neighborhoods and schools. Over half of the youth reported attending one of the nine ethnic-oriented, community-based ASPs that were identified for the study at least three times a week (Borden, et al., 2005).

The study showed that reasons for non-participation varied between ethnic groups, by age, and by gender. There were four main reasons for non-participation: youth "1) were too busy or lacked time, 2) had other interests, 3) held negative opinions of the youth center, or 4) were constrained from participation by parents or guardians" (Borden, et al., 2005, pg. 39). Some programs were perceived as boring or more suitable for younger students. In fact, for the students over age 15, the presence of younger children at the youth centers was described as a major deterrent to their enrollment and participation.

The popularity of the program was also a concern for some of the teenagers in the group. If the programs were not as popular or favorable to their peers, the youth were less likely to participate (Borden, et al., 2005).

The African American females in the group cited competing interests and negative opinions of the youth center in response to why they and their peers do not participate in some ASPs. The Latina girls repeatedly cited chores at home or babysitting as a major barrier to participation. Likewise, the Arab American females cited lack of time, often due to homework or babysitting, and lack of confidence as some of the major barriers to attendance in ASPs. The Arab American, Chaldean, and Latina girls also stated that they were not allowed to participate in sports like coed swimming and that some parents did not allow their daughters to go out at night for fear of involvement with males in the ASPs. The Arab American males in the group also cited parental disapproval, particularly in terms of work and study behaviors that served as a barrier to participation. As one participant expressed, "I joined the football team, but my dad made me quit because I had to work...my dad tells me that school is more important than work and work is more important than sports" (Borden, et al., 2005, pg. 40).

The Chaldean females in the group diverged a bit from the dialogue in that they believed that youth did not participate in ASPs because they were engaged in other risky but "fun" activities such as partying, smoking, or doing drugs (Borden, et al., 2005). Both the Chaldean females and the males in this group stated that their parents' concerns about safety were another 
barrier to participation in ASPs. The Chaldean males cited other extracurricular activities such as bike riding and sports as a major barrier to participation. The Latino males in the group mentioned that some youth did not participate because they were out getting high, doing drugs, or out with their girlfriends (Borden, et al., 2005). Other barriers to participation for the Latino males included: lack of information, money, shyness, and concerns over body image. Finally, the attendance barrier most commonly voiced by the African American males in the group was the quality of the program staff. If the program staff did not relate well to young people, that was seen as a major barrier to participation in ASPs.

\section{The Present Study}

This paper discusses a study designed to identify the reasons for non-attendance in a sample of dropouts from the Baltimore County Middle School After-School Collaboration Project (BCAP). This study offers some interesting results that may help program implementers develop methods that help decrease attrition rates and increase attendance in after-school programs. First, a brief description of BCAP is warranted.

\section{The Baltimore County Middle School After-School Collaboration Project}

The Baltimore County Middle School After-School Collaboration Project is a joint project between the Department of Criminology and Criminal Justice at the University of Maryland (UMD) and the Baltimore County Local Management Board (BCLMB). The BCLMB is the County agency in charge of facilitating collaboration across public and private child-serving agencies and presently funds, monitors, and evaluates a variety of after-school programs in the area (Gottfredson, 2004).

\section{Sample and Selection}

During the 2006-2007 school year, five Baltimore County Public Schools participated in BCAP. All of the schools were middle schools that served approximately 4,617 students from predominantly lower socioeconomic status and were predominantly African American. Upon parental consent, 447 students who expressed interest in participating and volunteered to participate in an after-school program across all five schools were randomly assigned to either receive the "enhanced" after-school program (the experimental group) or a "less intensive" after-school program (the control group). After randomization across all five school sites was completed, there were 223 students randomly assigned to the control group, and 224 students randomly assigned to the experimental group.

\section{The Experimental and Control Group Programs}

The "enhanced" after-school program had three main components: structured tutoring, life skills training, and attendance monitoring and reinforcement. The structured tutoring in math and reading was carried out by hired tutors and was intended to improve literacy and math skills. The life skills training curriculum was carried out by hired and trained program staff and was intended to "reduce substance use and increase social competency skills" (Gottfredson, 2004, pg. 2). Finally, the attendance monitoring and reinforcement component was also carried out by program staff and was intended to aid in program attendance via positive reinforcement (i.e. the students are given various material incentives for continually attending the program).

The ASP was held three days a week, three hours each day for a total of 30 weeks. The three program components mentioned above were the structured activities involved in the program. 
Less structured activities included a variety of sports, board games, dance, and active team games offered after the structured activities had been completed. The less intensive program required the control group students to attend the ASP on the last Thursday of every month. The last Thursday of every month was a day when no structured activities were carried out (i.e. the students played various games for three hours).

\section{Attrition in ASPS}

The aforementioned study ran from September, 2006 until May, 2007. This study examined the reasons for non-participation using a sample of the students who were randomly selected to participate in the "enhanced" ASP but eventually dropped out. Data was collected via phone interviews and surveys mailed out to the parent/legal guardian of the non-participant. Every effort was made to contact all of the dropouts who had withdrawn from the program as of January, 2007. Due to time constraints adolescents who dropped out after January, 2007 were not included in this study.

\section{Present Study Method}

\section{Interviews}

There were a total of 98 students withdrawn from the after-school program at the end of January, 2007. A student was withdrawn if he/she missed over $50 \%$ of the program days in a given month during the 2006-2007 school year. For example, during the month of January, the program ran for 14 days so the students were expected to attend the after-school program all 14 days. In theory, at the end of the month if a student had attended seven days or less, they were withdrawn from the program. Of the 98 students withdrawn from the program, 68 (69\%) students agreed to participate in a phone interview. This included 34 (50\%) girls and 34 (50\%) boys.

\section{Surveys}

Postcard surveys were mailed to the remaining 30 (31\%) dropouts who were difficult to contact by phone. A brief letter accompanied the survey and explained its purpose. Only two (7\%) of the 30 surveys were returned as the majority of the data was collected via phone interviews. Two male students completed and returned the survey mailed to their home address and 28 (93\%) of the 30 remaining students could not be reached by phone and did not return the survey in the mail.

\section{Results}

Several reasons for non-attendance were voiced by the adolescents and in some cases by both the adolescents and their parents. As such, several themes developed over the course of the interviews. It was possible to group the reasons for non-attendance into 20 distinct issues under two overarching categories. The first category is entitled "Program Complaints." Under this category were reasons for non-attendance that dealt with the internal workings of the program such as program fidelity, length, and structure. The second category dealt with more external reasons for non-attendance such as relocation, fatigue, and illness. Thirteen of the reasons for dropping out of the program are categorized as "Program Complaints," while seven other reasons for non-attendance are categorized as "External Concerns." Tables 1 and 2 show the most prevalent reasons for non-attendance. 
Table 1

Reasons for Non-Attendance: Internal Issues, $N=70$

\begin{tabular}{|l|c|}
\hline Program Complaints & $\begin{array}{c}\text { Percentage of students } \\
\text { who gave particular reason }\end{array}$ \\
\hline Program Fidelity $^{\mathrm{a}}$ & $21.4 \%$ \\
\hline Program was too long $^{\mathrm{b}}$ & $17.0 \%$ \\
\hline $\begin{array}{l}\text { Overall program was boring or was } \\
\text { not liked }^{\mathrm{c}}\end{array}$ & $16.0 \%$ \\
\hline Needed more academic help & $14.3 \%$ \\
\hline $\begin{array}{l}\text { All Stars component was not } \\
\text { liked/boring }\end{array}$ & $10.0 \%$ \\
\hline Forgetfulness/Miscommunication & d \\
\hline $\begin{array}{l}\text { Homework/tutoring component } \\
\text { was not liked/boring }\end{array}$ & $8.6 \%$ \\
\hline Too structured & $7.0 \%$ \\
\hline General concerns & $7.0 \%$ \\
\hline Program staff was too harsh & $7.0 \%$ \\
\hline Too little structure & $5.7 \%$ \\
\hline Concerns about safety & $3.0 \%$ \\
\hline No individualized attention & $1.4 \%$ \\
\hline
\end{tabular}

\footnotetext{
${ }^{a}$ Certain activities were advertised during the initial planning/recruitment phase such as photography-, music-, and dance-related activities. Not all advertised activities were carried out. Also, structured tutoring was supposed to be offered at all sites, but only some sites actually hired tutors.

${ }^{b}$ This was especially the case during the winter time when sundown was around 5 p.m. or so. Some of the students and parents did not like the length of time spent in the program because it was dark outside by the time the students returned home. Other students complained that they did not like staying at the afterschool program for three hours because it prevented or deterred them from participating in other activities when they returned home.

${ }^{\mathrm{c}}$ Some of the students said that the program was boring because they "never got to do anything." There was often some kind of behavioral issue that caused all of the students to spend a majority of the time being quiet and making up for the bad behavior of specific students.

${ }^{\mathrm{d}}$ Miscommunication problems included: receiving no instructions or receiving faulty instructions about the program days. For example, one student stated that because the school did not announce the meeting of the after-school program over the loud speaker, he would constantly forget to attend.

${ }^{\mathrm{e}}$ Included in this category are the students who said that they just did not feel like going and parents who had specific incidents that made them take their children out of the program.
} 
Table 2

Reasons for Non-Attendance: External Issues, $N=70$

\begin{tabular}{|c|c|c|}
\hline External Issues & \multicolumn{2}{|c|}{$\begin{array}{l}\text { Percentage of students who gave } \\
\text { particular reason }\end{array}$} \\
\hline \multirow{2}{*}{$\begin{array}{l}\text { Other after-school } \\
\text { activities }^{\mathrm{a}}\end{array}$} & Non-family-related & Family-related \\
\hline & $27.0 \%$ & $17.0 \%$ \\
\hline $\begin{array}{l}\text { Hang out with friends } \\
\text { outside of program }\end{array}$ & \multicolumn{2}{|l|}{$8.6 \%$} \\
\hline Moved & \multicolumn{2}{|l|}{$8.6 \%$} \\
\hline Behavioral problems & $\begin{array}{l}\text { Expelled from } \\
\text { school or program } \\
5.7 \%\end{array}$ & $\begin{array}{l}\text { Suspended from } \\
\text { school or program } \\
4.3 \%\end{array}$ \\
\hline Illness and/or fatigue ${ }^{b}$ & \multicolumn{2}{|l|}{$4.3 \%$} \\
\hline Grades dropped & \multicolumn{2}{|l|}{$4.3 \%$} \\
\hline Friends as a distraction ${ }^{c}$ & \multicolumn{2}{|l|}{$1.4 \%$} \\
\hline
\end{tabular}

\footnotetext{
a Other after-school activities included in the family category are: chores, baby-sitting siblings, "family time" and in the non-family category are: sports teams that were part of school or organized by an outside organization such as a local league, other after-school clubs such as chess and science clubs, cheerleading, and religious activities to name a few. This category also includes having to attend a funeral of a family member or tending to sick family members.

${ }^{\mathrm{b}}$ Included in this category is depression. One student in particular was suffering from depression and could not attend the after-school program.

${ }^{c}$ One student stated that his friends in the after-school program were a distraction because they would often try to involve him in mischievous behavior. Additionally, he was not able to focus on his homework because his friends wanted him to "mess around" with them instead.
}

Under external concerns, there were two main issues that yielded more specific reasons for non-attendance. This included participation in other after-school activities and behavioral problems. Some students were suspended from either the after-school program or their school for a period of time or were expelled from the program or their school if their behavior was too severe. Additionally, there were two types of other after-school activities that students participated in; those that were family-oriented such as babysitting siblings, doing chores around the house, or "family time," and those that were not family-oriented such as: participation in school-sponsored sports teams or clubs (i.e. the basketball team or the chess club), non-school sponsored clubs (i.e. dance club and boy scouts), and/or religious education classes.

Each statement made by the respondent was recorded and then coded. After all of the interviews were completed, there were 145 statements made regarding barriers to participation. This included 88 statements made regarding program complaints and 57 statements made regarding external concerns. The average number of internal reasons given was 1.3 per 
student and the average number of external reasons given was .8 per student. The average number of total reasons given for non-participation was two and the maximum number of reasons given was six. Sixty-three percent of the students gave at least one internal reason for non-participation and $67 \%$ of the students gave at least one external reason for nonparticipation. Finally, $30 \%$ of the students gave both internal and external reasons for nonparticipation.

Withdrawal interviews indicated that there were six primary reasons that students dropped out of the after-school program as listed in Table 3.

Table 3

Top Six Reasons for Withdrawal, $N=70$

\begin{tabular}{|l|c|}
\hline Reason given & $\begin{array}{c}\text { Percentage of students who gave } \\
\text { particular reason }\end{array}$ \\
\hline $\begin{array}{l}\text { 1) Engagement in other non-family oriented } \\
\text { after-school activities (i.e. dance club) }\end{array}$ & $27 \%$ \\
\hline 2) Lack of program fidelity & $21 \%$ \\
\hline $\begin{array}{l}\text { 3) Engagement in family-related, after-school } \\
\text { activities (i.e. babysitting siblings) }\end{array}$ & $18 \%$ \\
\hline 4) Program was too long & $17 \%$ \\
\hline 5) Boredom & $16 \%$ \\
\hline 6) Need for more academic help & $15 \%$ \\
\hline
\end{tabular}

In Weisman and Gottfredson's 2001 study, the main reason students gave for dropping out of the program was boredom. Boredom, however, was cited by only $16 \%$ of the dropouts in this study. Fifteen percent of the dropouts stated that they needed more academic help. Students in this category expressed concern over the lack of help in subject areas such as language arts, math, and reading - areas that they were struggling with in school. Moreover, a fraction of these students were actually taken out of the after-school program and placed in specialized tutoring programs in order to obtain the help they needed. Although "homework help" was a program component sometimes performed alongside tutoring, the majority of students in this group stated that homework help was either not given and/or was not sufficient for their particular assignments. A few of the students voiced their concerns over the inability of tutors and/or program staff to actually help them complete their homework because as one particular student stated, "they [the program staff] didn't know how to do it." This suggests that program staff members were not sufficiently trained to assist a student in completing their particular homework assignments. Altogether, more dropouts indicated that various aspects of the afterschool programming (i.e. concerns listed under program complaints) caused them to drop out (as opposed to the external issues). 


\section{Summary}

This study found more participant concern regarding the internal workings of the program (internal issues) than external issues. The top six reasons for non-attendance in the ASP were:

1. Engagement in non-family-related after-school activities,

2. Lack of program fidelity,

3. Engagement in family-related after-school activities,

4. Program length,

5. Boredom, and

6. Lack of quality academic help.

Although this study was modest, it speaks to the type of concerns that program dropouts may face in deciding not to participate in an after-school program.

The findings about program complaints suggest that this particular after-school program suffered from a lack of program fidelity, excitement, and quality academic help; in essence, issues that dealt with program design/structure and implementation. The lack of sufficiently trained program staff members may have been due to high staff turnover. The total turnover rate across all five schools was $55 \%$, with one of the schools having a turnover rate as high as $75 \%$. Theoretically, these issues should be addressed in the design phase of an after-school program; however, even careful research and planning may not be able to combat the unpredictable nature of adolescents, their decision-making skills, and their complex family structure. Additionally, careful planning may not be able to circumvent the tendency of program staff to seek alternative employment, especially if the students in after-school programs are particularly disruptive or display significant behavior problems.

\section{Implications}

Program implementers face a great challenge. They must balance the needs and wants of not only the adolescent, but the parent(s) as well. After-school programs and their activities have to be fun, exciting, academically-oriented, structured, but not too structured, safe, considerate of the adolescent's time, and sensitive to family issues/concerns. With all of these considerations it will be difficult to completely satisfy every need/want of the adolescent and their families. It is clear that quality after-school programming is beneficial to the adolescent and their families; however, it is less clear what the most effective strategy is for retention. Additionally, the problems that BCAP had with program fidelity, structure, and implementation may be unique to this research and as such, the results may not be generalizable to other students in other afterschool programs.

Most of the non-family-related after-school activities that the adolescents in this study were engaged in were clubs of some sort; for instance dance club, chess club, and sports clubs. These activities were structured, adult-supervised, after-school activities. This suggests that although it is common for ASPs to offer a wide variety of activities, it may be more beneficial to offer a specific, narrow set of age- and gender-specific activities. Likewise, program fidelity is key in retention efforts; if a program claims to offer a particular activity, then it is important to 
the students to be able to participate in that activity. Perhaps this is a good reason to offer a specific number of activities instead of an extensive number of activities that may or may not materialize. The expectation of something that may not materialize may be more detrimental to the student's future participation in ASPs than the expectation of certain non-varied activities at the ASP.

Related to this issue of an adolescent's time, boredom, the fifth highest reason on the list, manifested itself in a couple different ways. Some of the dropouts we interviewed stated that behavioral problems resulted in "time outs," which affected the ability of all of the students in the ASP to partake in the unstructured sports and games activities. Other dropouts stated that they found the monotony of the activities performed at the ASP to be a problem because the activities themselves were uninteresting.

The non-family-related activities that some of the dropouts participated in were dance clubs or organized sports clubs where they would practice the same routine for one, two, or three hours each day. At least for the dropouts in this category, these other after-school activities took precedence over the ASP. These structured monotonous activities were simply more "fun" and "interesting" than the unstructured, monotonous activities offered at the ASP. Again, it may be beneficial for program implementers to offer a narrow set of gender- and age-specific activities with clearly stated purposes and goals. This may decrease the number of students in a particular ASP, but help increase retention and engagement rates at the ASP. Tied closely to this issue is the fourth highest reason for non-participation: program length. When students are bored and uninterested, program length becomes a problem. When students are engaged and excited to be present, program length is less of a problem.

Eighteen percent of the dropouts in this study cited family-related after-school activities as a barrier to participation. Some students routinely watched their siblings after school, performed basic household chores, and/or spent time with a parent in a different household after school. For program implementers, these family-related after-school activities may be harder obstacles to overcome. However, when program implementers have some knowledge about an adolescent's commitments outside of the program, it should help them design programs that work around an adolescent's schedule. For example, some ASPs use "drop in" programs and activities with flexible schedules as recruitment and retention strategies for older youth who may have more demands on their time.

Finally, from this research, there is no indication that students were unwilling to participate in the academically-oriented activities at the ASP. Even the students who claimed that the academically-oriented components of the ASP were "boring," cited a few other reasons such as involvement in "other after-school activities" as the main barrier to participation. However, this study did find that some dropouts felt that there was a lack of quality academic help. The results imply that it is imperative that tutors, program staff, and helpers be knowledgeable in the student's coursework, especially in the particularly difficult areas of math, reading, and language arts. It may be beneficial to do one of two things: either conduct an assessment of the student's math, reading, history, language arts (and other subjects) skills and find out where the majority of the students are struggling, or access their student records in order to determine the areas that need improvement. Perhaps this manner of addressing academic concerns will help program implementers in the hiring process and help give students the tools they need to improve their academic skills and further their academic success. 


\section{Recommendations for Future Studies}

Future studies may want to take into consideration the challenges recognized in this study as they seek to develop after-school programming that suits the unpredictable needs of students and their families.

\section{References}

Borden, L.M., Perkins, D.F., Villarruel, F.A., \& Stone, M.R. (2005). To participate or not to participate: That is the Question. New Directions for Youth Development, 105, 33-49.

Carnegie Corporation. (1992). A matter of time. New York: Carnegie Corporation of New York.

Gottfredson, D.C., Gottfredson, D.G., \& Weisman, S.A. (2001). The timing of delinquent behavior and its implications for after-school programs. Criminology and Public Policy, 1, 61-86.

Gottfredson, D.C. (2004). The Baltimore County after-school collaboration project: Evaluation narrative, University of Maryland, College Park, Maryland.

Harvard Family Research Project. (2003). A review of out-of-school time program quasiexperimental and experimental evaluation results. Out-of-School Time Evaluation Snapshot, 1, $1-12$.

Harvard Family Research Project. (2004). Moving beyond the barriers: Attracting and sustaining youth participation in out-of-school time programs. Issues and Opportunities in Out-of-School Time Evaluation, 6, 1-16.

Herrera, C., \& Arbreton, A.J. (2003). Increasing opportunities for older youth in after-school programs: A report on the experiences of Boys \& Girls Clubs in Boston and New York City. Philadelphia, PA: Public/Private Ventures.

Hollister, R. (2003). The growth in after-school programs and their impact. Washington, D.C.: Brookings Roundtable on Children, Brookings Institution.

Lauver, S.C., \& Little, P.M. (2005). Recruitment and retention strategies for out-of-school-time programs. New Directions for Youth Development, 105, 71-89.

Rhodes, J.E. (2004). The critical ingredient: Caring youth-staff relationships in after-school settings. New Directions for Youth Development, 101, 145-161.

Simpkins, S.D., Ripke, M., Huston, A.C., \& Eccles, J.S. (2005). Predicting participation and outcomes in out-of-school activities: Similarities and differences across social ecologies. New Directions for Youth Development, 105, 51-69. 
Snyder, H., Sickmund, M., \& Poe-Yamagata, E. (1996). Juvenile offenders and victims: 1996 update on violence. Washington, D.C.: Office of Juvenile Justice and Delinquency Prevention.

Sickmund, M., Synder, H., \& Poe-Yamagata, E. (1997). Juvenile Offenders and Victims: 1997 update on violence. Washington, D.C.: Office of Juvenile Justice and Delinquency Prevention.

Weisman, S.A., \& Gottfredson, D. (2001). Attrition from after school programs: Characteristics of students who drop out. Prevention Science, 2, 201-205.

(C) Copyright of Journal of Youth Development Bridging Research and Practice. Content may not be copied or emailed to multiple sites or posted to a listserv without copyright holder's express written permission. Contact Editor at: patricia.dawson@oregonstate.edu for details. However, users may print, download or email articles for individual use.

ISSN 2325-4009 (Print); ISSN 2325-4017 (Online) 